\title{
An Analysis Of The Return Dependence Between Large And Small Capitalization Stocks
}

Rakesh Bali, (E-mail: bali@adelphi.edu), Adelphi University Hany Guirguis, Manhattan College

\begin{abstract}
In a Seemingly Unrelated Regression Estimation (SURE) framework, we examine the Grangercausal linkages between the monthly returns of small and large market capitalization stocks. Our initial results confirm that the returns of large stocks lead those of smaller stocks as reported by Lo and MacKinlay (1988). However, such causality disappears once we account for the small-firm January effect, the feedback of monetary policy, and the expectation of a recession. Thus, we attribute the lead-lag pattern correlation to model misspecification that fails to incorporate the macroeconomic environment and its seasonality.
\end{abstract}

\section{Introduction}

$\mathrm{n}$ an influential paper Lo and MacKinlay (1988) document that the monthly autocorrelation in the market returns is significantly positive. They claim that it is the behavior of small capitalization (cap) stocks that causes this effect and that it is not caused by infrequent trading alone. Campbell et al. (1997, p. 76) state, “... the correlation between current returns of smaller stocks and past returns of larger stocks is always larger than the correlation between the current returns of larger stocks and the past returns of small stocks." We hypothesize that in an economy where shocks (representing both systematic and unsystematic risks) to the aggregate cash flows are first reflected in the returns of large, well-capitalized firms, the data may indicate that the returns to small cap stocks trail those of large caps. However what needs to be understood is that it is the information dissemination that first takes place in the relative liquid secondary securities markets for these large cap stocks that aids price discovery. The information that indicates a systematic shock is than communicated to small caps and their returns respond in a lead-lag pattern.

There have been a few attempts to explain this relationship. Boudoukh et al. (1994) argue that this autocorrelation has been overstated and is most likely caused by institutional factors. McQueen et al. (1996) argue that there exists a directional asymmetry in the small stock concurrent and lagged response to large stock movements. They find that the cross-autocorrelation may be caused by various market frictions. They find that small stocks may underreact to good but not to bad news.

Our study jointly examines the lead-lag relationship among large and small cap returns. It extends the analysis by incorporating the effects of a change in the monetary policy and the expected state of the economy. The rationale for including these variables in our analysis is that the impact of these changes on the real economy is first reflected in the aggregate cash flows of large cap firms. This occurs because due to their very status large, wellcapitalized firms produce a larger share of GDP, employ a higher proportion of the workforce and are more likely to be using capital intensive state-of-the art equipment and hence can have disproportionate impact. Further, since their exist relatively liquid markets for their securities with high trading volume and low bid-ask spreads, their prices can quickly incorporate new information. To the extent that these shocks indicate systematic (non-diversifiable) risk, they influence large firms first and then the effect filters through to small firms. Thus, if the lagged return of small firms is driven by changes in the Fed's monetary policy or the threat of a recession, then upon their inclusion in the 
regression equation the relation between current returns on small firms and lagged returns of large firms should disappear.

It has been documented that the returns of small firms are higher in January than in other months (Keim (1983), and Fama and French (1992) etc.). Thus, if the January effect significantly influences the returns of small firms, then its inclusion in the regression equation eliminates the errors due to the omitted variable problem. This helps proper estimation of the relationship between current returns on small firms and lagged returns of large firms and affects our results significantly.

The outline of the paper is as follows. In section II, we describe the model and the data. In section III we provide the results and conclude.

\section{Data and Model}

We use the University of Chicago Center for Research in Security Prices (CRSP) monthly tapes to obtain the data for the computation of return quintiles for the time period between 1966:01 and 2001:12 for a total of 432 time series observations. The first two quintiles RETQ1 and RETQ2 are small caps. The returns of the large cap stocks are represented by the average returns of the fourth and fifth quintiles (RETQ4). The reason for averaging the returns is that the correlation coefficient between the two returns series is 0.97 . Thus, including the returns of both quintiles in the regression analysis creates severe multicollinearity, and increases the probability of type II error.

In examining the causality between the returns of small and large cap stocks, we first regress the returns of each of the four quintiles on a constant, the returns' first lag (RETQI $\left.t_{t-1}\right)$, and the first lag of the returns of the other three quintiles. To account for the dependence in the error terms across the returns of the four quintiles, we jointly estimate the four equations by Seemingly Unrelated Regression Estimation (SURE) as follows:

$$
\operatorname{RETQI}_{\mathrm{t}}=\alpha_{\mathrm{I}}+\sum_{\mathrm{I}=1}^{4} \beta_{\mathrm{I}} \cdot \operatorname{RETQI}_{\mathrm{t}-1}+\varepsilon_{\mathrm{t}}
$$

To address the problem in estimating the cross autocorrelation among the monthly returns of small and large cap stocks while ignoring other macro and financial variables, we include additional independent variables in the four return equations. The first is a dummy variable that equals 1 in January (JAN) and 0 elsewhere. We also include the first lag of the change in Federal funds rate $\left(\Delta \mathrm{R}_{\mathrm{t}-1}\right)$ in each equation. While there are a number of options for the monetary measure, we follow McCallum (1983), Bernanke and Blinder (1992), Laurent (1988), Leeper (1992), Sims $(1986,1992)$ and Morgan (1993), and choose the change in the Federal funds rate as our measure of monetary policy actions. It has been recognized that much, if not most, of recent monetary policy changes have been implemented through changes in the funds rate. Finally, we include the Stock and Watson Experimental Leading recession index (REC) to account for the anticipated changes in the economy. This index gives the probability of a recession in six months. These shocks represent the systematic and unsystematic risks that the aggregate cash flows of large firms are exposed to. Thus our second system of equations is specified as follows:

$$
\operatorname{RETQI}_{\mathrm{t}}=\alpha_{\mathrm{I}}+\sum_{\mathrm{I}=1}^{4} \beta_{\mathrm{I}} \cdot \mathrm{RETQI}_{\mathrm{t}-1}+\delta_{\mathrm{I}} \cdot \mathrm{JAN}_{\mathrm{t}}+\gamma_{\mathrm{I}} \cdot \Delta \mathrm{R}_{\mathrm{t}-1}+\eta_{\mathrm{I}} \cdot \mathrm{REC}_{\mathrm{t}}+\varepsilon_{\mathrm{t}}
$$

\section{Regression Results and Conclusion}

The estimates of SURE (1) are reported in Table 1 Panel A. As predicted by the lead-lag hypothesis the current returns of the first quintile (the smallest quintile) trail the returns of large stocks (RETQ4) in a significant fashion. Upon the inclusion of the dummy variable for January, change in the Federal funds rate, and the leading recession index in SURE (2) we first observe that the adjusted $\mathrm{R}^{2}$ rise significantly (double). In addition, the January dummy, $\Delta \mathrm{R}_{\mathrm{t}-1}$ and REC are significant and the lagged returns of the large stocks turn insignificant. The slope coefficients on January decline monotonically as size increases. The magnitude of the coefficient estimate on the 
federal funds rate increases with size. These results support our conjecture that the large firm effect we describe is important and that the lead-lag pattern in large-small cap returns can be understood in a framework consistent with market efficiency. Development of a theoretical framework incorporating the feedback between the stock returns and the macroeconomic environment is left for future research.

\section{References}

1. Bernanke, B. and A. Blinder. (1992) The Federal Funds Rate and the Channels of Monetary Transmission, American Economic Review, 82(4), 901--21.

2. Boudoukh, J., M. Richardson, and R. Whitelaw. (1994) A tale of three schools: Insights on autocorrelations of short-horizon stock returns, Review of Financial Studies, 7(3), 539--73.

3. Campbell, J., A. Lo and C. Mackinlay. (1997) The econometrics of financial markets (Princeton University Press, Princeton, NJ).

4. McQueen, Grant, Michael Pinegar, and Steven Thorley. (1996) Delayed reaction to good news and the cross-autocorrelation of portfolio returns, Journal of Finance, 51(3), 889--920.

5. Fama, E. and K. French. (1992) The cross section of expected stock returns, Journal of Finance, 47(2), 427--66.

6. Gali, Jordi. (1992) How well does the IS-LM model fit postwar US data, Quarterly Journal of Economics, 107(2), 709--38.

7. Keim, D. K. (1983) Size-related anomalies and stock return seasonality: Further empirical evidence, Journal of Financial Economics, 12(1), 13--32.

8. Laurent, R. D. (1988) An interest rate-based indicator of monetary policy, Economic Perspectives (Federal Reserve of Chicago), 12, 3--14.

9. Leeper, E.M. (1992) Facing up to our ignorance about measuring monetary policy effects, Economic Review (Federal Reserve Bank of Atlanta), 77, 1--16.

10. Lo, A. and C. MacKinlay. (1988) Stock market prices do not follow random walks: Evidence from a simple specification test, Review of Financial Studies, 1, 41--66.

11. King, Robert and Mark Watson. (1992) Comparing the fit of dynamic models, Working paper, Northwestern University.

12. McCallum, B. T. (1983) A reconsideration of Sims' evidence concerning monetarism, Economics Letters, 13, 167--71.

13. Morgan, D. (1993) Asymmetric effects of monetary policy, Economic Review (Federal Reserve of Bank of Kansas City), Second Quarter, 21--33.

14. Sims, Christopher A. (1986) Are forecasting models usable for policy analysis, Quarterly Review (Federal Reserve Bank of Minneapolis), Winter, 2--16.

15. Sims, Christopher A. (1992) Interpreting the macroeconomic time series facts: The effects of monetary policy, European Economic Review, 36, 975--1011. 
Table 1

Seemingly Unrelated Regression estimate of the lead-lag relation among the returns of large and small cap firms (SURE (1)) is shown in Panel A. RETQ4 is the mean return of quintiles 4 and 5 since they are highly correlated (coefficient is .99). SURE (2) is estimated by adding the January dummy, the lagged change in the Federal funds rate and the recession index and presented in Panel B.

\section{Panel A}

\begin{tabular}{lllll} 
& RETQ1 $_{\mathbf{t}}$ & RETQ2 $_{\mathbf{t}}$ & RETQ3 $_{\mathbf{t}}$ & RETQ4 $_{\mathbf{t}}$ \\
\hline Adj. $^{2}$ & 0.16 & 0.13 & 0.10 & 0.07 \\
Constant $^{2}$ & $1.71^{* * *}$ & $0.93^{* * *}$ & $0.86^{* * *}$ & $0.97 * * *$ \\
RETQ1 $_{\mathrm{t}-1}$ & -0.17 & -0.16 & -0.14 & -0.10 \\
RETQ2 $_{\mathrm{t}-1}$ & 0.29 & 0.05 & -0.01 & -0.10 \\
RETQ3 $_{\mathrm{t}-1}$ & -0.11 & 0.13 & 0.10 & 0.14 \\
RETQ4 $_{\mathrm{t}-1}$ & $0.50^{*}$ & 0.34 & 0.34 & 0.19 \\
\hline
\end{tabular}

Panel B

\begin{tabular}{lllll} 
& RETQ1 $_{\mathbf{t}}$ & RETQ2 $_{\mathbf{t}}$ & RETQ3 $_{\mathbf{t}}$ & RETQ4 $_{\mathbf{t}}$ \\
\hline Adj. $\mathrm{R}^{2}$ & 0.39 & 0.27 & 0.20 & 0.12 \\
Constant & $0.99^{* *}$ & 0.62 & $0.83^{* *}$ & $1.21^{* * *}$ \\
RETQ1 $_{\mathrm{t}-1}$ & -0.04 & -0.10 & -0.12 & -0.11 \\
RETQ2 $_{\mathrm{t}-1}$ & 0.21 & 0.04 & 0.03 & -0.00 \\
RETQ3 $_{\mathrm{t}-1}$ & -0.02 & 0.16 & 0.09 & 0.01 \\
RETQ4 $_{\mathrm{t}-1}$ & 0.29 & 0.19 & 0.21 & 0.12 \\
JAN & $13.06^{* * *}$ & $8.06^{* * *}$ & $5.80^{* * *}$ & $2.26^{*}$ \\
$\Delta \mathrm{R}_{\mathrm{t}-1}$ & $-0.78^{*}$ & $-0.79^{*}$ & $-0.90^{* *}$ & $-0.91^{* *}$ \\
REC & $0.03^{* *}$ & $0.02^{* *}$ & $0.02^{* *}$ & $0.02^{* *}$ \\
& & & & \\
\hline
\end{tabular}

*** indicates significance at the $1 \%$ level.

$* *$ indicates significance at the $5 \%$ level.

* indicates significance at the $10 \%$ level. 